Doi:10.5212/PublicatioHum.v.17i1.101106

\title{
A CRIANÇA, O BRINCAR E O CORPO: POSSIBILIDADES A PARTIR DA TEORIA DE FRIEDRICH FROEBEL
}

\author{
CHILD, PLAY AND BODY: POSSIBILITIES \\ ACCORDING TO FRIEDRICH FROEBEL'S THEORY
}

\author{
Daiana Camargo ${ }^{1}$ \\ Maria Isabel Moura Nascimento \\ Profa. Dra. Silvia Christina Madrid Finck
}

“A raiz do homem é o próprio homem [...].

Na práxis, o homem tem de comprovar a verdade, isto é, a realidade, o poder e a mundanalidade de seu pensamento.” (MARX, 1984)

Recebido para publicação em 13/04/2009

Aceito para publicação em 28/05/2009

\section{RESUMO}

Considerando a ênfase dos estudos em educação a respeito do brincar e sua valorização no ambiente escolar, remetemo-nos, neste artigo, à história da educação infantil, mais precisamente às propostas de Friedrich Froebel, objetivando desenvolver uma análise da função do brincar no desenvolvimento e a aprendizagem da criança. Tratamos, a seguir, do papel do brincar para a escola, na perspectiva de uma educação integral e inclusiva, que atenda às necessidades do homem e da sociedade contemporânea. Tendo em conta as especificidades do brincar, abordamos a necessidade de reflexão acerca do brincar corporal como meio facilitador do desenvolvimento integral e da aprendizagem.

Palavras-chave: Froebel. Brincar. Educação. Corpo.

\begin{abstract}
Considering the emphasis given in education to the importance of play and its value in the school environment, in this article the history of child education and the proposals of Friedrich Froebel are discussed aiming to develop an analysis of the function of play in children's development and learning. The role of play for school according to an whole and inclusive perspective to education that meets the needs of men in contemporary society is also discussed. Having in mind the special features involved in play, the need to reflect about play as a facilitating tool for children's whole development and learning are discussed.
\end{abstract}

Keywords: Froebel. Play. Education. Body.

${ }^{1}$ Aluna do Curso de Mestrado em Educação da Universidade de Ponta Grossa, UEPG. E-mail: camargo.daiana@ig.com.br 


\section{Friedrich Froebel e a criação do Jardim de Infância: um espaço para o lúdico}

Ao adentrarmos a história da educação, verificamos a valiosa contribuição da obra do alemão Friedrich Froebel para a configuração da educação infantil nos moldes que a vivenciamos contemporaneamente. De acordo com Eby (1976), Froebel pode ser considerado o reformador educacional de maior expressividade no século XIX. Considerando que até meados do século XVIII a criança era vista como adulto em miniatura, grandes foram os avanços a partir das abordagens de Rousseau, Pestalozzi e Froebel para a compreensão da criança como ser único e dotado de capacidades específicas. (CAMBI, 1999; EBY, 1976).

Em relação à criança, Kishimoto (2002) enfatiza que nos tempos primitivos a imagem desta era relacionada a deuses da mitologia, sendo assim explicada a capacidade criativa do homem, enquanto para Froebel a criança é imagem e semelhança de Deus, para que se reconheça a perfeição do homem e seja valorizada e espontaneidade expressiva do ser.

Filho de pastor protestante, órfão de mãe e em convívio com a hostilidade de sua madrasta, relata Eby (1976, p. 431) que "entregue, assim, a seus próprios recursos, o sensível coração do menino voltou-se para as colinas, flores, árvores e nuvens, em busca de companhia”. Esta relação com a natureza terá grande influencia em sua proposta pedagógica e em seus escritos sobre educação, nos quais enfatiza sempre o valor do contato do homem com seu ambiente natural e o respeito para com este.

Ainda na mocidade, e diante de grande inquietação sobre seu futuro profissional, o rapaz pôde experimentar a tarefa de ensinar, a qual foi reconhecida como atividade que, de acordo com Eby (1976) correspondia aos anseios de Froebel. Cambi (1999) relata que, diante da experiência em Yverdon junto a Pestalozzi, torna-se crítico dos pressupostos do estudioso suíço, ressaltando, após observações e experiências, a fragilidade do método por este empregado.

Sua característica investigadora e crítica fizeram do jovem alemão um dedicado estudioso dos assuntos relacionados à educação. Em sua obra A educação do homem, publicada em 1826, aborda a necessidade de valores morais, contato com a natureza e enfatiza a ideia de que o menino é um homem em potencial - noções que o integram ao grupo de educadores que defendiam uma visão romântica de infância, como enfatizam Manacorda (1989) e Arce (2002).

Froebel afirma que a educação é o processo pelo qual o indivíduo desenvolve a condição humana autoconsciente, com todos os seus poderes funcionando completa e harmoniosamente, em relação à natureza e à sociedade. Além do mais, era o mesmo processo pelo qual a humanidade, como um todo, originariamente se elevara acima do plano animal e continuara a se desenvolver até sua condição atual. Implica tanto a evolução individual quanto a universal. (EBY, 1976, p. 435).

A respeito da educação da criança, Froebel dedica-se à organização de uma metodologia específica para esta faixa etária, o que constitui o “coração" do método froebeliano, embasada em estudos que deram origem a diversas obras, tratando da formação do homem e sua educação. (CAMBI, 1999).

A pedagogia froebeliana enfatizava o importante papel da atividade da criança, cabendo ao professor descobrir o talento de cada educando. Arce (2002) ressalta que a relação Deus, natureza e humanidade era denominada “unidade vital”, tendo a educação a tarefa de propiciar o pleno desenvolvimento. De acordo com Koch (1985), citado por Arce (2002), eram três os pontos fundamentais na metodologia froebeliana, e consistiam em: seguir o modelo da perfeição humana de Jesus; reconhecer a existência de Deus no homem e na natureza; e a função do educador de respeitar o desenvolvimento espontâneo do educando. A aprendizagem é considerada o resultado da vida ativa da criança, cabendo ao educador auxiliar o novo conhecimento a brotar de um anterior, de um velho conhecimento. O desenvolvimento autêntico provém da atividade espontânea, extraindo da criança suas potencialidades.

A compreensão do desenvolvimento humano por fases foi outra grande contribuição de Froebel para a educação, o que possibilitou a compreensão das necessidades específicas da criança, e que, segundo ele, impressionavam pela gradação e continuidade, e, além disso, a unidade que abraça 
todas as fases de desenvolvimento, como descreve Eby (1976).

A linguagem, para Froebel, é o primeiro meio que a criança utiliza para a expressão de seus sentimentos e imagens interiores, e reconhece a importância do desenho para aumentar o conhecimento e conduzir ao pensamento abstrato. Diante da grandiosa contribuição de Friedrich Froebel, destaca-se a importância do brinquedo e da brincadeira na prática educativa, considerados como germes de toda a vida posterior. É através do jogo e do brincar que a criança expressa como vê o mundo e, segundo Arce (2002), trata-se de uma atividade importante para realmente conhecer a criança.

Brincadeira. - A brincadeira é a fase mais alta do desenvolvimento da criança - do desenvolvimento humano neste período; pois ela é a representação autoativa do interno - representação do interno, da necessidade e dos impulsos internos. A brincadeira é a mais pura, a mais espiritual atividade do homem neste estágio e, ao mesmo tempo, típica da vida humana como um todo - da vida natural interna escondida no homem e em todas as coisas. Por isso ela dá alegria, liberdade, contentamento, descanso interno e externo, paz com o mundo. Ela tem a fonte de tudo que é bom. A criança que brinca muito com determinação autoativa, perseverantemente até que a fadiga física proíba, certamente será um homem (mulher) determinado, capaz do autossacrifício para a promoção do bem estar próprio e dos outros. Não é a expressão mais bela da vida da criança neste momento, uma criança brincando? - uma criança totalmente absorvida em sua brincadeira? - uma criança que caiu no solo tão exausta pela brincadeira? Como já indicado, a brincadeira neste período não é trivial, ela é altamente séria e de profunda significância. Cultive-a e crie-a, mãe; proteja-a e guarde-a, pai! Para a visão calma e agradável daquele que realmente conhece a Natureza Humana, a brincadeira espontânea da criança revela o futuro da vida interna do homem. As brincadeiras da criança são as folhas germinais de toda a vida futura; pois o homem todo é desenvolvido e mostrado nelas, em suas disposições mais carinhosas, em suas tendências mais interiores. (FROEBEL, 1887, p. 55, apud ARCE, 2002, p. 60-61).

Considerando a abordagem teórica a respeito da importância do lúdico para o desenvolvimento infantil, Froebel criou brinquedos chamados de “dons”, ofertas divinas para atender as necessidades e peculiaridades da criança. De acordo com Cambi (1999) e Kishimoto (2002), esses brinquedos devem auxiliar a criança a ter iniciativa, compreender a natureza, apreender formas do real, desenvolver sua fala, representar o imaginário e expressar sua criatividade. O material é composto de bola, cubo, cilindro, divisões de cubos formando blocos para construção. As "ocupações” consistiam de formas de trabalho manual simples. Ao abordar o jogo, Froebel define o mesmo como forma de trabalho para a criança, visto que para ele o trabalho consistia uma forma de elevação do espírito do homem. Sua proposta, segundo Kramer (1993), pode ser compreendida como “currículo por atividades”, no qual o lúdico é a base de toda a ação pedagógica.

Oliveira (2002) enfatiza que a utilização dos jogos ou "dons" vinha acompanhada de canções, com o intuito de educar as emoções e sensações. A autora, ao tratar jogo na pedagogia froebeliana, ressalta a importância deste diante de suas vantagens intelectuais, morais e de seu valor par a o desenvolvimento físico da criança. Para Eby (1976, p. 450): "O movimento é a fonte de sentido de ritmo. Nenhum educador conferiu maior valor cultural ao ritmo que Froebel.” Arce (2004) reforça que o melhor método, de acordo com Froebel, baseava-se no agir pensando e pensar agindo, para evitar que o ensino fosse algo abstrato a ponto de prejudicar o desenvolvimento dos talentos da criança.

No ano de 1837 é fundada a primeira instituição destinada à educação da infância, denominada Kindergarten, expressão interpretada como jardim de infância, adaptando-se a nomenclatura à proposta de desenvolvimento natural da criança, valorização de suas potencialidades e liberdade para a atividade criadora, semelhantes a um jardim, que carece cuidados, porém onde as plantas crescem de acordo suas peculiaridades - aspectos estes bem evidenciados na trajetória de Froebel como educador e estudioso.

\section{O brincar e a escola na sociedade do século XXI}

A partir da contribuição de Froebel para efetivação de uma educação voltada para as peculiaridades da infância, muitas foram as mudanças até a configuração da educação infantil que hoje conhe- 
cemos. Verificamos que, mesmo depois de passados dois séculos das considerações froebelianas acerca do lúdico, a prática pedagógica da educação infantil ainda negligencia o valor desta atividade como primordial para a aprendizagem da criança.

Estudiosos e pesquisadores enfatizaram, ao longo do tempo, a relevância do brincar e suas implicações no contexto educacional e no desenvolvimento da criança, porém os professores, ao serem questionados sobre o papel do brincar no ambiente educativo, ainda apresentam discurso equivocado em relação a sua utilização, com respostas oscilando entre brincar como atividade livre e meramente recreativa, ou discursos de que o lúdico auxilia no desenvolvimento integral da criança, relatando, porém, que a prática está desvinculada, presa a rotinas maçantes e tarefas repetitivas, com enfoque geralmente no preparo para a alfabetização, como destacam Catunda (2005) e Seber (1995).

Verificamos que as pesquisas apontam diversas possibilidades e necessidades relacionadas à educação da criança. A evolução social e tecnológica nos faz refletir sobre como estão agindo os seres humanos diante de tantas inovações, e como estamos absorvendo as mesmas, e incorporando-as (ou não) em nossa vivência cotidiana. A mudança de paradigma em relação ao ser humano nos faz questionar como estamos tratando nossas crianças hoje, e repensar a ideia de que investir nestas é "pensar no futuro". Olivier (apud MARCELLINO, 2003) e Catunda (2005).

Diante dessa perspectiva de aceleração e produção, perdemos de vista as reais necessidades e potencialidades da infância, o lúdico, o imaginário, a criatividade, a magia... que certamente influenciarão positivamente o ser do futuro, se bem vividas hoje. Um brincar e um aprender para aproveitar as inesgotáveis possibilidades que a infância proporciona diante da consolidação de valores, da construção de uma personalidade íntegra e sadia, do respeito a si, ao próximo e à natureza, permitindo que a criança cometa erros sem sentir-se culpada.

E qual o papel da escola neste contexto? Como a escola trata a criança e seu brincar? Como o professor percebe as necessidades e capacidades do pequeno educando?... Muitos são os questionamentos que nos inquietam, e que autores como Kishimoto (1998), Moyles (2002), Oliveira (2002), Olivier (apud MARCELLINO, 2003) e Seber
(1995) apontam em suas obras, no intuito de indicar reflexões e possíveis ações que venham a modificar a compreensão do lúdico e sua utilização na prática pedagógica.

O papel ideológico da escola caracteriza-se pela transmissão dos valores considerados hegemônicos, o que, segundo Olivier, leva a uma "conformação social”, deixando de lado as relações afetivas, as vivências prazerosas, em prol de uma obrigação sistematizada, em busca da racionalidade, produtividade, eficiência e sucesso financeiro; deixa-se de viver o agora para projetar-se num futuro incerto, sem pensar no que a criança é, e sim no que ela vai ser, ignorando as particularidades de cada ser, o modo de vida de cada criança e as especificidades que ela traz consigo, em relação ao ambiente social no qual se insere. Marcellino (1990; apud MARCELLINO 2003) "acredita que precisam ser levados em conta, no processo de aprendizagem, a criança e sua cultura, tanto considerando os conteúdos quanto a forma”.

Reencontrar o lúdico, entender o seu valor revolucionário, torna-se imperativo se se deseja preservar os valores humanos no homem. Da mesma forma, através dela podemos resgatar a criatividade, ousando experienciar o novo, acordar do estado vegetativo, improdutivo, disfuncional do corpo ou da mente e escolher tornar-se homem, resistindo às experiências de vida desumanizantes, acreditando em si, em suas ideias, sonhos e visões, elementos, entre outros, percebidos como intrínsecos dos homens e da humanidade. (OLIVIER apud MARCELLINO, 2003, p. 31).

Diante das indagações já feitas sobre a escola, verificamos a necessidade de que esta seja um ambiente agradável, que possibilite a socialização e o autoconhecimento de seus alunos, que valorize a expressão criativa, a arte, o movimento, o lúdico, o contato com a natureza e consigo mesmo; que seja um local de encontro humano, vinculando saber e prazer. (ARCE, 2002; ROMERA, apud MARCELLINO, 2003; e OLIVEIRA, 2002). Neste contexto, Catunda (2005) enfatiza que:

Aprender requer, além de ambiente favorável, amor e alegria por parte daquele que ensina, o que torna o aprendizado mais eficaz, posto que é vivido com prazer. Temos dificuldades de aprender o que não se nos apresenta como significativo. 
Consideramos que reside no brincar uma imensa gama de possibilidades de compreensão da criança e de atuação para com a mesma, e que cabe ao adulto a tarefa de tentar apropriar-se deste brincar como facilitador das relações humanas e pedagógicas, pois, como observa Mello (apud MARCELLINO, 2003), o adulto se expressa mediante palavras, enquanto a criança se expressa por meio das atividades exercidas sobre seus brinquedos.

O brincar é uma atividade séria, que deve ser respeitada pelo adulto. Enquanto o adulto dedica toda sua atenção e dedicação ao seu trabalho, a criança o faz para o brincar, sendo este repleto de significados, pois para ela, segundo Seber (1995), seriedade, alegria, esforço e interesse são sentimentos que não se opõem, empenhando no ato de brincar o mesmo esforço que dedica ao andar, falar ou comer. Esta atividade favorece, conforme enfatiza Oliveira (2002), o equilíbrio afetivo da criança, possibilitando que ela tome posse de signos sociais já constituídos, exigindo dela uma transformação gradativa das formas com que se relaciona com o mundo, por intermédio da comunicação interpessoal, negociação de regras e dos papéis que assume ao construir sua brincadeira. A criança desenvolve, assim, a memória, sua representação de mundo, de si e do outro, sente prazer ao brincar e envolve-se em valiosas situações de emoção e afetividade.

Moyles (2002) enfatiza que o brincar, além do meio de aprendizagem que representa, permite que adultos perceptivos e competentes possam aprender sobre as especificidades da criança, obtendo dessa forma um ponto de partida que auxilie na aquisição de novas aprendizagens. É brincando que a criança experimenta o mundo adulto e representa a sua compreensão deste. O brincar permite que corpo e cérebro estejam ativos, o que motiva e desafia a criança na busca de novas informações e conhecimentos, podendo representar, por vezes, a fuga da realidade, para evitar uma situação que não lhe agrada ou a qual a criança não compreende.

Devido à relevância do brincar para as crianças e à sua motivação para ele, o brincar deve estar impregnado nas atividades de aprendizagem apresentadas às crianças, em vez de ser considerado um estorvo ou uma atividade residual.

A utilização do brincar na escola, por vezes de modo equivocado, traz à tona as discussões entre brincar e trabalho, diante da ideia de que o brincar representa o ócio, e que as atividades para serem representativas à aprendizagem precisam necessariamente estar vinculadas a uma rotina rígida e a uma metodologia tradicional de transmissão de conteúdos. Os educadores, como abordam Kishimoto (1998) e Tardif (2000), precisam voltar ao passado e analisar sua própria vida, sua relação com o brincar, o prazer e o aprender, visto que na constituição do ser enquanto pessoa, suas vivências e concepções são entendidas como parte importante de seu processo de formação e atuação profissional.

Autores como Kishimoto (1998), Moyles (2002) e Seber (1995) abordam a relação entre aprendizagem, prazer e trabalho, e destacam que a escola precisa romper com este paradigma socialmente construído, e desvincular o aprender do poder e da dominação, para aproveitar no fazer pedagógico a infinidade de possibilidades que a criança traz consigo, para que se oriente a construção da aprendizagem.

Só assim se poderá realizar o sonho dos educadores de que o brincar seja valorizado pelos pais e pela sociedade em geral, mas a modificação da compreensão do lúdico na escola precisa partir da mudança de concepção dos educadores e da utilização efetiva do brincar no cotidiano escolar.

\section{A criança, o brincar e o corpo: possibilidade de desenvolvimento integral}

A partir das reflexões apresentadas sobre o papel do brincar na prática educativa, para o desenvolvimento integral da criança, verificamos que este brincar apresenta-se de diferentes formas, com características próprias em cada fase pela qual a criança passa ao longo da infância. Da apreensão e compreensão do mundo por meio do movimento à sistematização e organização do brincar, da imitação ao faz de conta, o corpo está sempre em movimento, seja este mais intenso ou organizado, pois a criança utiliza toda a sua energia e seu corpo para a interação com o mundo que a cerca. De acordo com Moyles (2002, p. 33):

Por meio do brincar livre, exploratório, as crianças aprendem alguma coisa sobre situações, pessoas, 
atitudes e respostas, materiais, propriedades, textura, estruturas, atributos visuais, auditivos e cinestésicos. Por meio do brincar dirigido, elas têm outra dimensão e uma nova variedade de possibilidades estendendo-se a um relativo domínio dentro daquela área ou atividade.

Assim, o brincar nas suas mais variadas formas, utiliza-se de toda a capacidade de expressão corporal que a criança possui, ou que esta constrói ao longo de sua interação com o meio. Para os diferentes momentos da vida, os sistemas corporais apresentam diferentes níveis de desenvolvimento e ritmos. A criança necessita, dessa maneira, oportunidades de utilizar o corpo e movimento para interagir com o mundo, atividades que, segundo Souza (apud MARCELLINO, 2003) "tenham ressonância na alma das crianças".

Ao tratar do movimento implícito no ato de brincar, Seber (1995) enfatiza que o domínio dele interfere diretamente nos relacionamentos sociais e nos sentimentos, visto que, quando o pensamento da criança se desenvolve, é por meio dos movimentos que esta se expressa, e posteriormente por meio da linguagem. Dantas (apud KISHIMOTO, 1998) reforça o valor do movimento, observando que a própria incontinência motora, a alegria do movimento pelo movimento, natural da criança, gera conflitos com o adulto, que não é capaz de compreender tal expressão, visto que o desejo do adulto, mesmo que não explicitado em palavras, seja de imobilidade e silêncio.

O brincar corporal, assim denominado por Moyles (2003), caracteriza-se como uma das formas mais representativas do lúdico, cabendo ao professor garantir o desenvolvimento da aprendizagem em seus diversos fatores, sejam eles intelectual, físico, moral, social, ético ou estético, numa compreensão abrangente de aprendizagem. A criança precisa compreender a si mesma e ter confiança em suas capacidades para o desenvolvimento de sua autonomia.

As atividades corporais precisam proporcionar bem-estar físico, mental e emocional à criança, a expressão corporal é forma de linguagem e não pode ser negligenciada pelo educador, pois se a criança tem dificuldade de se expressar pela linguagem, ela o faz de outras formas, e obtém satisfação ao fazê-lo. Brincar leva ao criar, criar com a mente e com o corpo.
Torna-se preocupante, diante das observações e vivências em relação ao brincar corporal e as abordagens de Marinho (2007), Moyles (2002) e Souza (apud MARCELLINO, 2003), o descaso em relação ao corpo como instrumento de ludicidade, considerando que as atividades referentes ao brincar físico são as menos oportunizadas na escola, ou então são vítimas de controle e coerção, não levando em conta que as crianças possuem necessidade real de atividade física intensa, bem como desvaloriza a criança como ser em potencial, tornando a mesma massa de manipulação de uma estrutura educacional enrijecida e frustrante. Catunda (2005, p. 28) ressalta que:

Auxiliar na construção de pessoas que possam viver sua corporeidade com plenitude, partindo de uma prática corporal lúdica, em que sejam respeitadas as individualidades, o ritmo de cada um, percebendo que somos diferentes não há como educar com fórmulas fechadas e verdades sem contestações, é um desafio a ser vencido com muita luta. Luta, principalmente, porque deveremos sair do senso comum e partirmos para uma prática que exigirá cientificidade e mudança de atitudes por parte dos professores e alunos.

O corpo, de acordo com Marinho (2007), é o caminho para o mundo interior, para a subjetividade. Representa a alegria, a vivacidade, a emoção e a fantasia, que se manifestam, na criança, por meio das representações lúdicas, no brincar e no jogo. A educação precisa abordar não só a vida intelectiva do aluno, mas também sua vida afetiva, corporal, social e espiritual, em busca do reencantamento do processo ensino-aprendizagem.

\section{Considerações finais}

Muitas são as considerações e inquietações em relação ao brincar e à prática educativa. Froebel, sua teoria e seus brinquedos trouxeram ao campo da educação grandiosa contribuição, e inovações significativas para a época e o contexto educacional em que foram desenvolvidas, possibilitando uma maior compreensão das peculiaridades educativas da criança, abrindo espaço para uma educação infantil centrada no ser em potencial. A visão de criança e educação evolui consideravelmente ao longo do tempo, muitos são os estudos e as des- 
cobertas, porém o brincar continua no centro das atenções e investigações acerca do desenvolvimento e da educação da criança.

A abordagem do brincar e suas especificidades devem estar presentes nas discussões a respeito da educação infantil, para que sua função e utilização no ambiente educacional possam ser adequadamente compreendidas e aplicadas.

O brincar corporal integra esta ampla rede de possibilidades oferecidas pela atividade lúdica, para a formação integral do ser, e precisa ser mais bem aproveitado na escola.

\section{Referências}

ARCE, A. Friedrich Froebel: o pedagogo dos jardins de infância. Petrópolis, RJ: Vozes, 2002.

O jogo e o desenvolvimento infantil na teoria da atividade e no pensamento educacional de Friedrich Froebel. Caderno Cedes, Campinas, v. 24, n. 62, p. 9 -25, abril 2004.

CAMBI, F. História da pedagogia. São Paulo: Editora ENESP, 1999.

CATUNDA, R. Brincar, criar, vivenciar na escola. Rio de Janeiro: Sprint, 2005.

EBY, F. História da educação moderna: teoria, organização e práticas educacionais. Porto Alegre: Globo, 1976.

KISHIMOTO, T.M. (Org). O brincar e suas teorias. São Paulo: Pioneira Thomson Learning, 2002.

KRAMER, S. (Org). Com a pré-escola nas mãos: uma alternativa curricular para a educação infantil. São Paulo: Ática, 1993.

MANACORDA, M. A. História da educação: da antiguidade aos nossos dias. São Paulo: Cortez: Autores Associados, 1989.

MARCELLINO, N. C. Lúdico, educação e educação física. Ijuí, RS: Ed. Unijuí, 2003.

MARX , Karl. 1848: manifest der kommunistischen partei. MEW Bd. 04, 1972, p.459-493 (Manifesto Comunista, in Obras Escolhidas, vol.1. São Paulo: AlfaÔmega, [s/d].

MARINHO, H. R. B et al. Pedagogia do movimento: universo lúdico e psicomotricidade. Curitiba: IBPEX, 2007.

MOYLES, J. Só brincar? O papel do brincar na educação infantil. Porto Alegre: Artmed, 2002.

OLIVEIRA, Z. R. Educação infantil: fundamentos e métodos. São Paulo: Cortez, 2002.
SEBER, M. G. Psicologia do pré-escolar: uma visão construtivista. São Paulo: Moderna, 1995.

TARDIF, M. Saberes profissionais dos professores e conhecimentos universitários: elementos para uma epistemologia da prática profissional dos professores e suas consequências em relação à formação para o magistério. Revista Brasileira de Educação, jan./fev./mar./abr. 2000. 
